\title{
Parasitaemia in Asymptomatic Bantu and Baka Pygmy People Living in the East Region, Cameroon
}

\author{
Gangueu Djape Clotilde Diane ${ }^{1 *}$, Yondo Jeannette ${ }^{2}$, Noumedem Anangmo Christelle \\ Nadia $^{2}$, Nkouayep Vanessa Rosine ${ }^{1}$, Atiokeng Tatang Rostang Joel ${ }^{1}$ and Mpoame Mbida ${ }^{1}$ \\ ${ }^{1}$ Department of Animal Biology, Faculty of Science, University of Dschang, Cameroon \\ ${ }^{2}$ Department of Biological Sciences, Faculty of Medicine and Pharmaceutical Sciences, University of Dschang, Cameroon
}

*Corresponding author: Gangueu Djape Clotilde Diane, Department of Animal Biology, Faculty of Science, University of Dschang, PO Box: 67, Dschang, Cameroon

\begin{abstract}
Background: Asymptomatic malaria constitutes a silent threat to an efficient malaria control strategy. The aim of this study was to assess the level of malaria parasitaemia tolerated by asymptomatic individuals in Baka pygmies and the Bantus of the East Region, Cameroon.

Methods: A community-based cross-sectional study was conducted among asymptomatic Bantu and Baka pygmies from 6 months aged to 76-years-old. A questionnaire was used to collect information from 1032 consenting participants about ethnicity, gender, age, level of education, occupation, anti-malarial treatment, seasonality and time spent in the forest. Blood were collected in EDTA tubes and thin and thick blood smear were prepared and parasite densities determined. Data was analyzed using SPSS 22.0. $t$-test and two-ways analyze of variance were performed to compare the log-transformed mean intensities. P-values less than 0.05 were taken as statistically significant. The results were expressed as mean \pm standard deviation (range).
\end{abstract}

Results: The mean malaria parasitaemia of Baka pygmies

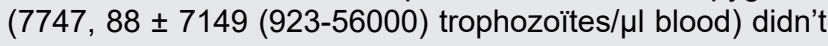
differ from that of Bantus $(8239,54 \pm 8642$ (462-72000) trophozoïtes/ $\mu$ l blood) $(P=0.56)$. Bantu's men carried higher parasitaemia (9429 \pm 3256 (667-72000) trophozoïtes/ $\mu \mathrm{l}$ blood) compared to females (7280 \pm 3301 (462-43429) trophozoites/ $\mu$ l blood). In Bakas, women had a significant $(P=0.02)$ mean parasitaemia $(8274 \pm 8306(923-56000)$ parasites $/ \mu$ l blood) compared to male $(6888 \pm 4608$ (121225333) trophozoites/ $\mu$ l blood). In general, infants of less than 2-years-olds had the least Plasmodium parasitaemia (4353 \pm 3772 (636-20444) parasites/ $\mu$ l blood). Among Bantus, workers in logging company tolerated the highest mean parasitaemia (9241 \pm 3428 (4706-12000) parasites/ $\mu$ l blood respectively) whereas in Bakas, students carried the highest mean parasitaemia (8855 \pm 7834 (1455-40000) parasites/ $\mu \mathrm{l}$ blood). In the general population short rainy season $(P=$ $0.00)$ and spending more time in the forest $(P=0.04)$ were factors associated with higher parasitaemia. In the Bakas communities, people who went to secondary school were more resistant $(16735 \pm 21919(5200-49600)$ parasites/ $\mu \mathrm{l}$ blood) to malaria parasite whereas in the Bantus, they had the least mean parasitaemia (6760 \pm 6177 (462-27200) parasites/ $\mu$ l blood).

Conclusion: At the end of this work it was noticed that in Baka as well as in Bantu, asymptomatic people were able to handle up to 55000 trophozoites/ $\mu$ l blood without any sign of the disease. Plasmodium parasitaemia depended mainly by the age, levels of education, season, and the time spent in the forest, and not by ethnicity as earlier hypothesized.

\section{Keywords}

Malaria, Asymptomatic, Parasitaemia, Ethnicity, Plasmodium

\section{Introduction}

Despite all the invested control measure, malaria is still an important public health threat in Cameroon, the whole country being at risk [1]. About $41 \%$ of the population suffers at least one episode of malaria each year, with pregnant women and under five-years-old children being the most vulnerable [2]. In the country, Plasmodium falciparum is responsible for the highest number of cases causing about $50 \%$ of medical consultations, $48 \%$ of hospital admissions and $30 \%$ of total morbidity [3].

Asymptomatic malaria, a previously neglected par-

Citation: Diane GDC, Jeannette Y, Nadia NAC, Rosine NV, Joel ATR, et al. (2020) Parasitaemia in Asymptomatic Bantu and Baka Pygmy People Living in the East Region, Cameroon. Int J Trop Dis 3:039. doi.org/10.23937/2643-461X/1710039

Accepted: November 09, 2020; Published: November 11, 2020

Copyright: (c) 2020 Diane GDC, et al. This is an open-access article distributed under the terms of the Creative Commons Attribution License, which permits unrestricted use, distribution, and reproduction in any medium, provided the original author and source are credited. 
asite reservoir, is actually recognized as a potential lagging factor, a silent threat to an efficient malaria control strategy [4]. The persistence of asymptomatic parasitaemia inside indigenous communities is a threat since asymptomatic individuals are parasite reservoirs who prevent the achievement of the malaria elimination goal [5]. So this study on asymptomatic people is important to evaluate the threshold parasite density above which a clinical malaria episode can start. In high malaria endemic areas, partial immunity against malaria tends to be high to the extent that majority of malaria infected individuals are normally asymptomatic. Estimating malaria parasite density is necessary for patients' management especially when parasite resistance to available therapy is increasing [6]. Not withstanding, a good mastery of the parasite control strategies, nature of transmission, epidemiological features, type of habitat as well as the role of ethnicity may be important to control parasitic load among asymptomatic individuals.

In fact, studies have shown that there isa disparity between the malaria risks of different tribes' sharing the same geographical area, with indigenous people often being more at risk [7]. Therefore, some peculiarities linked to ethnic groups may influence the level of tolerance to parasitic load and also fuels the spread of the infection from the reservoirs. The aim of this study was to assess the level of malaria parasitaemia that an asymptomatic individual can tolerate in the malaria en- demic area of the East-Cameroon. Such information especially concerning indigenous asymptomatic people, is lacking in our country although it may be important in setting up new malaria control programs.

\section{Methods}

\section{Study period, area and population}

This community-based cross-sectional study was conducted from May 2018 to April 2019 in the Nkouak health sector, East Region of Cameroon.

Nkouak is a Congo Basin forest village situated between Abong Mbang (24 km West) and Mindourou (29 km East), in the Upper Nyong division of Cameroon. The study area is situated at latitude $3^{\circ} \mathrm{N}$ and longitude $13^{\circ} \mathrm{E}$ and it covers an area of about $20 \mathrm{~km}$ of distance $[8,9]$. Nkouak Integrated Health Sector covers two health facilities including Nkouak integrated health sector where the study was conducted. The sector serves 4315 residents distributed among 8 small villages. Some of these are occupied mainly with Bantus (Nkouak, Nongbwala, Djouyaya, Etsiek, Kagnol) while others are occupied mainly with Baka Pygmies (Mballam II, Cyrie, Mayos) Figure 1.

Nkouak health sector is supplied by several permanent rivers like Dja and Nyong rivers which surround the study area. The climate of the area is a classical equatorial one characterized by two rainy seasons (from

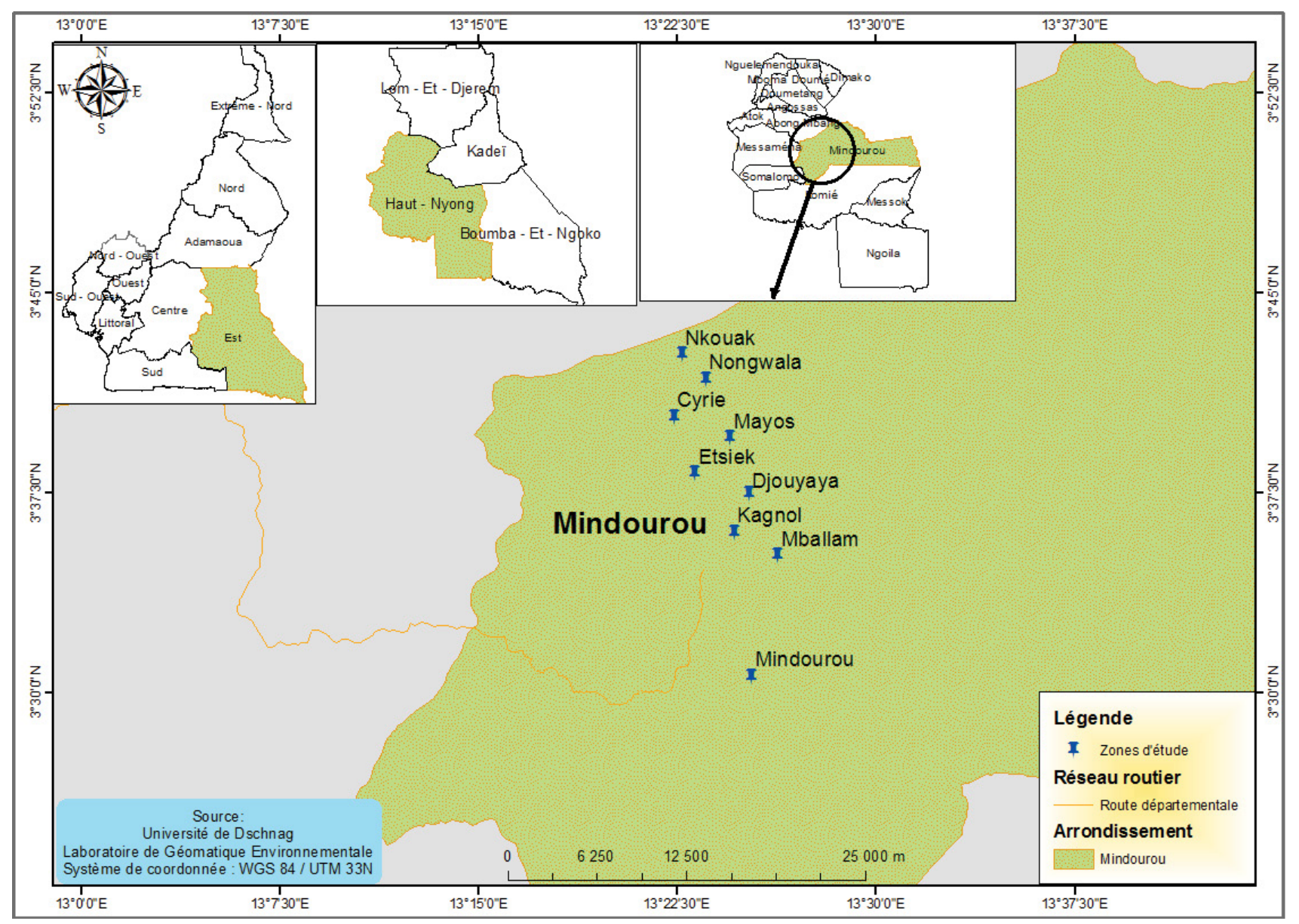

Figure 1: Nkouak health sector (Source: Laboratory of geomatic, University of Dschang, 2020). 
March to June and from August to November) and two dry seasons (from June to August and from November to March). The annual average temperature varies between $23^{\circ} \mathrm{C}$ and $28^{\circ} \mathrm{C}$, with a high atmospheric humidity all year round $[9,10]$. The average rainfall varied between $1600 \mathrm{~mm}$ and $2000 \mathrm{~mm} /$ year. The vegetation is characterized with an evergreen transitional forest and a semi-deciduous dense and moist forest [8].

Nkouak is mainly a farming locality. Some of the people are employed by Forest logging Companies like PALLISCO, FIPCAM, DINO et Fils. Malaria is the main mosquito-borne disease in that locality and as such a public health problem of primary importance.

\section{Sampling technique}

To obtain the sample size, the statistical formula of Yamane (1967) was used:

$$
\mathrm{n}=\frac{\mathrm{N}}{1+\mathrm{N}(\mathrm{e})^{2}}
$$

$\mathrm{n}$ : sample size; $\mathrm{N}$ : population size; e: sampling error or precision (5\%).

According to the last population inventory in the Abong-Mbang health district in 2018, the population of the Nkouak health sector was estimated at 4315 individuals. From this population size, a sample of 366 individuals was obtained. To better represent the population in the study, we collected 1032 samples with 631 Bantus and 401 Bakas.

The survey involved malaria asymptomatic volunteer participants from two ethnic groups: Baka Pygmies and Bantus. In this study, was considered as asymptomatic, anybody who presented no symptom of malaria on the day of data collection (fever, shivering, headache, articular pains etc.). A structured questionnaire was administered to the participants who gave their consent. Community health delegates translated the questionnaire into local language for participants who were unable to read, write or understand Frenchor English. Confidentiality of the information provided was ascertained to the participants. In fact, only the principal investigator had access to questionnaire which contained personal information on the participant. Laboratory manipulation was based on numerical code addressed to identify each participant. The questionnaire contained independent variables such as ethnicity, gender, age, level of education, occupation, anti-malarial treatment, seasonality and time spent in the forest.

The interview with participants and blood collection took place in the community house of each village. Blood was collected using EDTA test tubes either by finger prick or by venous swab according to the participant's desire [11].

\section{Blood staining procedure}

A thick blood smear (about $6 \mu$ lof blood) and a thin smear ( $2 \mu$ l of blood) were prepared from each blood sample. The smears were stained with $10 \%$ Giemsa after fixing the thin smear with absolute methanol [12].

The blood smears were then examined using the oil immersion objective. Slides were reported negative for parasites only after observing at least 50 fields. Parasite density was determined by counting the number of malaria parasites against 200 white blood cells and expressing the resultant number of parasites/ $\mu$ l blood assuming a white blood cell count of 8000 per $\mu$ l of blood [13]. Thin films were examined to confirm the parasite species identified on the thick film. Blood slide was declared positive when a concordant result was produced by two competent microscopists.

\section{Estimation of parasite density}

Parasite densities were recorded as a ratio of parasites to WBC in thick films as follows [12]:

Parasite density $($ in parasite $/ \mu 1$ blood $)=\frac{\text { Number of parasites counted } \times 9000}{\text { Number of } W B C \text { counted }}$

\section{Data analysis}

Data was analyzed with the Statistical Package for Social Sciences (SPSS), version 22.0. Those data were firstly log-transformed. t-test for independent sample and two ways analyze of variances were performed to compare the mean parasite densities. Statistical significance was set at $P \leq 0.05$.

\section{Ethical approval}

The study was conducted under the ethical clearance number 2018/05/1036/CE/CNERSH/SP delivered by the Cameroon National Ethical Committee for Research on Human Health. All volunteers participating in human landing catches signed a written informed consent form indicating their willingness to take part in the study.

\section{Results}

\section{Characteristics of the study population}

The overall population of this study was 1032 with 401 Baka pygmies and 631 Bantus. Table 1 described the basic characteristics of the population.

From this table, we observed that people of less than 2 years and those above 50-years-old were the less represented in Baka pygmies as well as in Bantus. There was no Baka who attended higher education and only one Bantus reached that education level in the study area. Only one Baka's civil servants and nine Bantus were recorded in the study. In the Bantus, 144 over 631 referred to modern antimalarial treatment whereas only 9 Baka referred to the same treatment went they suffers from malaria.

The prevalence of Plasmodium infection was $46.6 \%$ and $46.4 \%$ in Baka and Bantus. In the general population, infants of less than 2-years-old were the most 
Table 1: Characteristics of the study population.

\begin{tabular}{|c|c|c|c|c|}
\hline Parameters & Variables & Baka & Bantu & Total \\
\hline \multirow{2}{*}{ Gender } & Female & 272 & 409 & 681 \\
\hline & Male & 129 & 222 & 351 \\
\hline \multirow{5}{*}{$\begin{array}{l}\text { Age }[14,15] \\
\text { (years-old) }\end{array}$} & $<2$ & 23 & 49 & 72 \\
\hline & $2-5$ & 97 & 156 & 253 \\
\hline & $6-15$ & 83 & 151 & 234 \\
\hline & $16-50$ & 189 & 253 & 442 \\
\hline & 51-years-old and above & 9 & 22 & 31 \\
\hline \multirow{4}{*}{ Levels education } & No instruction & 129 & 192 & 321 \\
\hline & Primary education & 258 & 278 & 536 \\
\hline & Secondary education & 14 & 160 & 174 \\
\hline & Higher education & 0 & 1 & 1 \\
\hline \multirow{6}{*}{ Profession } & Farmers & 201 & 165 & 366 \\
\hline & Students & 64 & 182 & 246 \\
\hline & Civil servants & 1 & 9 & 10 \\
\hline & House workers & 133 & 243 & 376 \\
\hline & Forest operators & 2 & 19 & 21 \\
\hline & Traders & 0 & 13 & 13 \\
\hline \multirow{7}{*}{ Treatment } & NT & 2 & 11 & 13 \\
\hline & SM & 6 & 198 & 204 \\
\hline & MT & 9 & 114 & 123 \\
\hline & TT & 188 & 92 & 280 \\
\hline & $\mathrm{SM}+\mathrm{MT}$ & 7 & 42 & 49 \\
\hline & $\mathrm{SM}+\mathrm{TT}$ & 133 & 115 & 248 \\
\hline & $\mathrm{SM}+\mathrm{MT}+\mathrm{TT}$ & 7 & 38 & 45 \\
\hline \multirow{4}{*}{ Seasons } & MRS & 111 & 185 & 296 \\
\hline & MDS & 121 & 156 & 277 \\
\hline & SRS & 120 & 172 & 292 \\
\hline & SDS & 49 & 118 & 167 \\
\hline \multirow{5}{*}{ Time spent in the forest } & Never go through the forest & 8 & 33 & 41 \\
\hline & Journal & 193 & 467 & 660 \\
\hline & weeks & 113 & 77 & 190 \\
\hline & Months & 60 & 37 & 97 \\
\hline & Years & 27 & 17 & 44 \\
\hline \multicolumn{2}{|l|}{ Total } & 401 & 631 & 1032 \\
\hline
\end{tabular}

Table 2: Variation of Plasmodium parasitaemia according to ethnicity.

\begin{tabular}{|c|c|c|c|}
\hline Ethnic groups & Prevalence & $\begin{array}{l}\text { Mean parasitaemia } \\
\text { (Plasmodium/ } \mu \text { blood) }\end{array}$ & $\begin{array}{l}\text { Range } \\
\text { (Plasmodium/ } \mu \text { l blood) }\end{array}$ \\
\hline Baka & $46.6 \%$ & $7748 \pm 7149$ & $923-56000$ \\
\hline Bantu & $46.4 \%$ & $8240 \pm 8642$ & $462-72000$ \\
\hline
\end{tabular}

infected (52.8\%), in the same ways, Bakas and Bantus who have never attended school education were the most infected (52.6\%). The less efficient anti-malarial treatment those people used was the combination of self-medication, traditional and modern treatments (51.1\% prevalence). The small rainy season was the season of intense malaria transmission in the general population (57.2\%). Globally, comparing to people who spent years in the forest, those who spent only a day time and who went back in the village in the evening were largely more infected (49.8\%).

\section{Variation of Plasmodium parasitaemia according to ethnic group}

Table 2 shows the variation of Plasmodium parasitaemia according to ethnicity. The mean of Plasmodium 
parasitaemia in Baka pygmies (7748 \pm 7149 Plasmodi$u m / \mu \mathrm{l}$ blood) didn't differ $(P=0.56)$ from that of Bantus (8240 \pm 8642 Plasmodium/ $\mu$ l blood).

\section{Plasmodium parasitaemia according to ethnic group and gender}

In the general population (Baka and Bantu take together), gender had no influence on the ability of people to support high Plasmodium parasitaemia $(P=0.25)$. Asymptomatic Bantu males carried higher parasitaemia compared to females $(P=0.07)$. In Bakas, men and women had approximately the same mean parasitaemia (6888 \pm 4608 (1212-25333) and $8274 \pm 8306$ (923$56000)$ parasites $/ \mu$ l blood respectively). Ethnicity did not influence the gender distribution of parasitaemia ( $P$ $=0.23$ ).

Distribution of Plasmodium parasitaemia according to ethnic groups and age
Table 3 presents the distribution of Plasmodium parasitaemia in asymptomatic individuals according to age and ethnic groups.

Elderly Baka people (51-years-old and above) were not included in the statistical analysis since only one was positive to malaria test. In general, age had a significant effect on the ability of people to tolerate high Plasmodium parasitaemia $(P=0.00)$. Infants of less than 2 years of age had the lowest Plasmodium parasitaemia (4353 \pm 3772 (636-20444) parasites/ul blood). A higher parasitaemia occurred in older individuals (2-5 and 6-15 years-old). Parasitaemia dropped again in the last age groups (16-50 and > 50-years-old). This same general trend was observed in each ethnic group except that Baka infants (less than 2-years-old) were slightly more resistant than Bantu infants (5736 \pm 4949 (1212-20444) and $3547 \pm 2684$ (636-11636) parasites/ $\mu$ l blood respectively in Baka and Bantu). The effect of age on parasitae-

Table 3: Variation of Plasmodium parasitaemia according to age and ethnic groups.

\begin{tabular}{|c|c|c|c|c|}
\hline \multirow{2}{*}{$\begin{array}{l}\text { Age [14,15] } \\
\text { (years) }\end{array}$} & \multicolumn{3}{|c|}{ Log. mean parasitaemia \pm Standard Deviation (Parasites $/ \mu$ l blood) } & \multirow{2}{*}{ P-value (Baka and Bantu) } \\
\hline & Baka & Bantu & Total & \\
\hline$>2$ & $3.64 \pm 0.32$ & $3.44 \pm 0.33$ & $3.51 \pm 0.34$ & 0.75 \\
\hline$(2-5)$ & $3.8 \pm 0.31$ & $3.8 \pm 0.40$ & $3.8 \pm 0.36$ & 0.95 \\
\hline$(6-15)$ & $3.86 \pm 0.31$ & $3.8 \pm 0.37$ & $3.82 \pm 0.34$ & 0.36 \\
\hline$(16-50)$ & $3.7 \pm 0.34$ & $3.74 \pm 0.4$ & $3.72 \pm 0.37$ & 0.4 \\
\hline $50<$ & 4 & $3.7 \pm 0.27$ & $3.73 \pm 0.27$ & 0.3 \\
\hline$P$-value & 0.04 & 0.00 & 0.00 & 0.02 \\
\hline
\end{tabular}

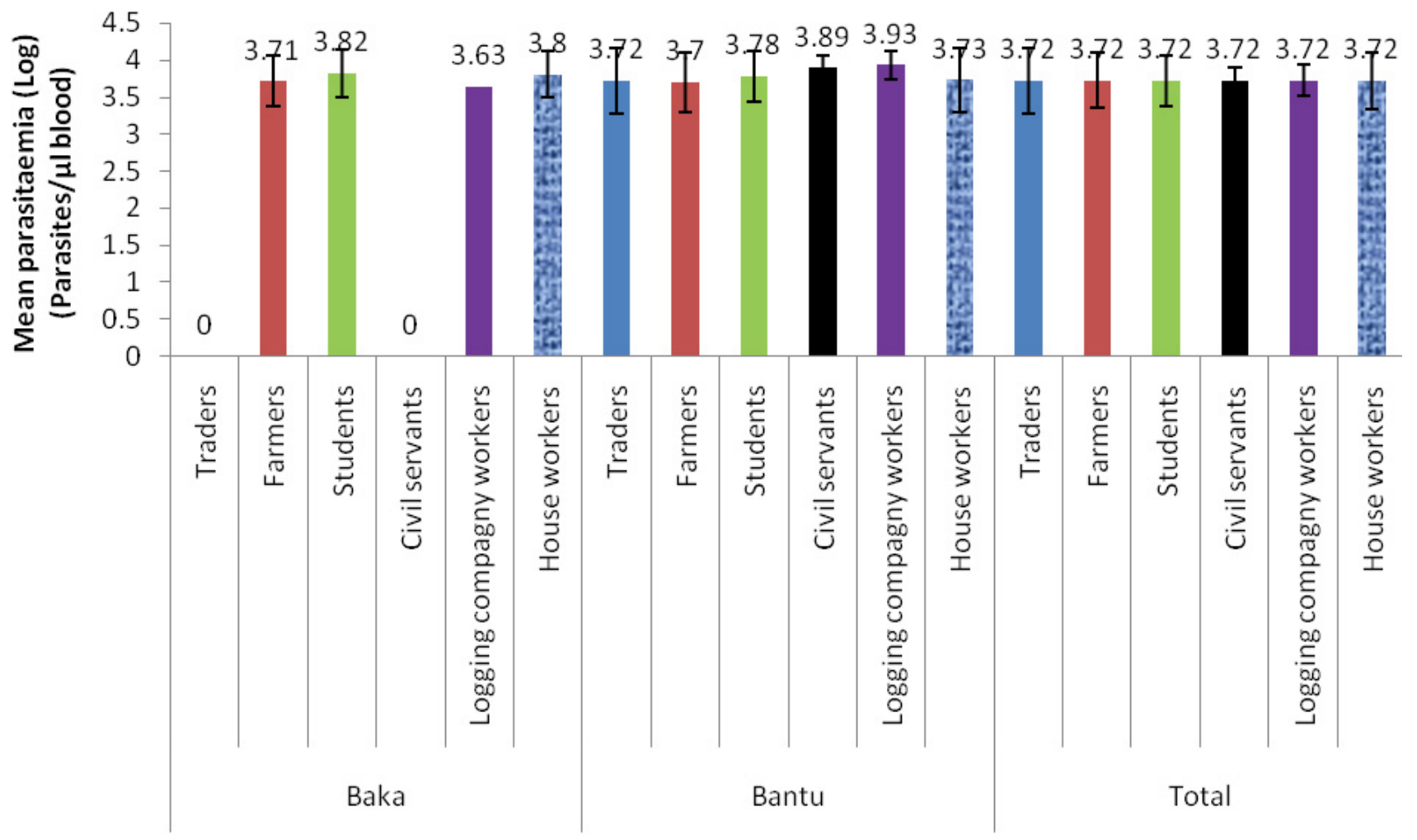

Main occupations

Figure 2: Variation of Plasmodium parasitaemia according to occupation and ethnicity. 
mia was influenced by ethnicity $(P=0.02)$.

\section{Plasmodium parasitaemia according to the occu- pation and ethnic group of participants}

Figure 2 described the variation of Plasmodium parasitaemia in malaria asymptomatic individuals with respect to different occupations and ethnicity.

Figure 2 shows that in the Baka, neither trader nor civil servant were infected with Plasmodium parasites. Logging company workers parasitaemia was lower (4286 (4286-4286) parasites/ $\mu$ l blood) but higher in students than in people of others occupations $(8855 \pm 7834$ (1455-40000) parasites/ $\mu$ l blood). In the Bantus, forest logging company workers carried the highest Plasmodium parasitaemia (9242 \pm 3428 (4706-12000) parasites/ $\mu$ l blood). Globally, famers tolerated approximately the same Plasmodium parasitaemia, irrespective to ethnic group.

Plasmodium parasitaemia in relation to type of anti-malarial treatment and ethnicity

Figure 3 shows the variation of Plasmodium parasitaemia in asymptomatic carriers according to type of anti-malarial treatment taken and ethnicity.

People who have never taken any anti-malarial treatment presented the lowest Plasmodium parasitaemia (3646 \pm 1874 (1311-5622) parasites/ $\mu$ l blood). The highest parasitaemia occurred in people treating themselves with a combination of traditional, modern treatment and self-medication (9337 \pm 7403 (151726667) parasites $/ \mu$ l blood). Plasmodium parasitaemia of Bantus people combining traditional treatment with modern treatment and self-medication was not significantly higher compare to the parasitaemia of people using others treatment $(P=0.7)$. The highest Plasmodium parasitaemia (11000 \pm 471 (10667-11000) parasites/ $\mu$ l blood) was observed in Baka pygmies who treated themselves with a combination of self-medication and modern treatment. But in general, the effect of treatment on parasitaemia was not influenced by ethnicity $(P=0.8)$.

\section{Plasmodium parasitaemia according to the level of education and ethnicity}

Table 4 describes the relationship between parasitaemia, levels of education and ethnic group.

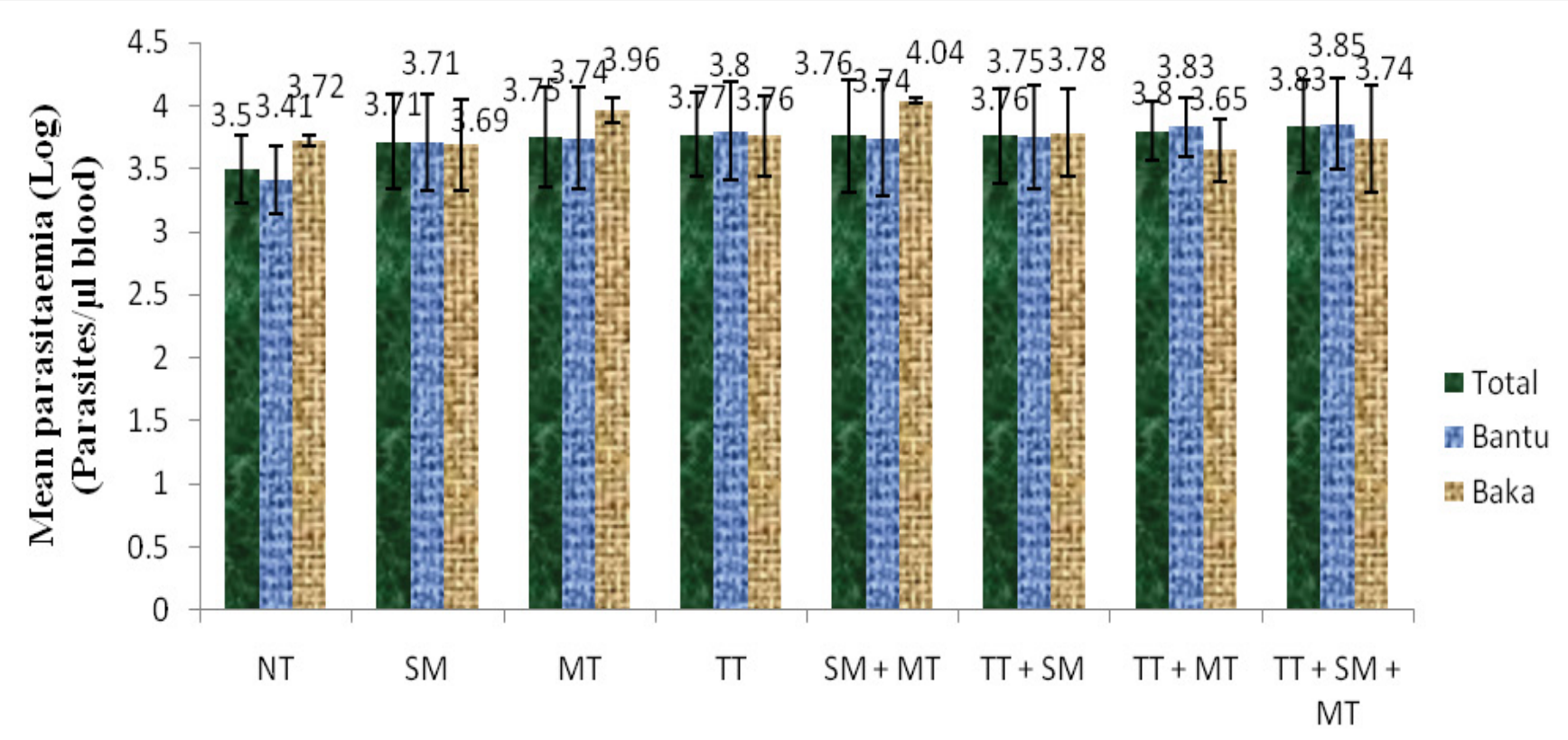

Anti malarial treatments

Figure 3: Plasmodium parasitaemia according to type of treatment and ethnicity. *SM: Self-Medication; MT: Modern Treatment; TT: Traditional Treatment; NT: No Treatment

Table 4: Variation of parasitaemia according to the levels of education and ethnicity.

\begin{tabular}{|c|c|c|c|c|}
\hline \multirow{2}{*}{ Levels of education } & \multicolumn{3}{|c|}{$\begin{array}{l}\text { Log. mean parasitaemia } \pm \text { Standard Deviation } \\
\text { (Parasites/ } \mu \text { l blood) }\end{array}$} & \multirow[t]{2}{*}{$P$-value (Baka and Bantu) } \\
\hline & Baka & Bantu & Total & \\
\hline No modern education & $3.8 \pm 0.33$ & $3.73 \pm 0.42$ & $3.76 \pm 0.38$ & 0.2 \\
\hline Primary education & $3.73 \pm 0.32$ & $3.80 \pm 0.34$ & $3.77 \pm 0.33$ & 0.1 \\
\hline Secondary education & $3.99 \pm 0.47$ & $3.4 \pm 0.43$ & $3.66 \pm 0.44$ & 0.1 \\
\hline$P$-value & 0.13 & 0.02 & 0.09 & 0.02 \\
\hline
\end{tabular}


Globally, Table 4 shows that people who attended up to the secondary education had the lowest Plasmodium parasitaemia (7330 \pm 7891 (462-49600) parasites/ $\mu$ l blood). In the opposite, Bakas who attended that secondary education had the highest Plasmodium parasitaemia (16735 \pm 3514 (5200-49600) parasites/ $\mu$ l blood) whereas in Bantus, it was the contrary $(P=0.02)$. In the Bantus, participants who attended only primary education were significantly more infected than others $(P=$ $0.02)$. The effect of levels of education on parasitaemia was influenced by ethnic group $(P=0.02)$.

\section{Plasmodium parasitaemia according to seasonali- ty and ethnicity}

Table 5 describes how Plasmodium parasitaemia varies in asymptomatic people by season and by ethnic group.

Table 5 shows that the highest Plasmodium par- asitaemia occurred during the small rainy season $(P=$ 0.00) $(9053 \pm 8614$ (1833-56000) and $11288 \pm 11825$ (1250-72000) parasites/ $\mu$ l blood in Bakas and Bantus respectively). Bakas as well as Bantus carried the lowest parasitaemia during the main rainy season $(5910 \pm 5862$ (923-26667) parasites/ $\mu$ l blood and $5226 \pm 5489$ (46225778) parasites/ $\mu$ l blood respectively). Ethnic group influenced the seasonal distribution of parasitaemia $(P$ $=0.00$ ).

\section{Variation of parasitaemia according to the time spent in the forest and ethnicity}

Figure 4 describes the variation of Plasmodium parasitaemia in asymptomatic people according to the time spent in the forest and ethnicity.

The level of parasitaemia was significantly influenced by the amount of time people spent in the forest $(P=0.00)$. In fact, the longer in stays in the forest,

Table 5: Variation of Plasmodium parasitaemia according to the season and ethnicity.

\begin{tabular}{|c|c|c|c|c|}
\hline \multirow{2}{*}{ Seasons } & \multicolumn{3}{|c|}{ Log. mean parasitaemia \pm Standard Deviation (Parasites $/ \mu \mathrm{l}$ blood) } & \multirow{2}{*}{ P-value (Baka and Bantu) } \\
\hline & Baka & Bantu & Total & \\
\hline MRS & $3.60 \pm 0.38$ & $3.52 \pm 0.42$ & $3.54 \pm 0.41$ & 0.3 \\
\hline MDS & $3.79 \pm 0.3$ & $3.84 \pm 0.31$ & $3.82 \pm 0.3$ & 0.3 \\
\hline SRS & $3.83 \pm 0.32$ & $3.89 \pm 0.36$ & $3.87 \pm 0.34$ & 0.2 \\
\hline SDS & $3.72 \pm 0.25$ & $3.63 \pm 0.33$ & 3. $66 \pm 0.30$ & 0.2 \\
\hline$P$ value & 0.007 & 0.00 & 0.00 & 0.00 \\
\hline
\end{tabular}

"MRS: Main Rainy Season; MDS: Main Dry Season; SRS: Small Rainy Season; SDS: Small Dry Season

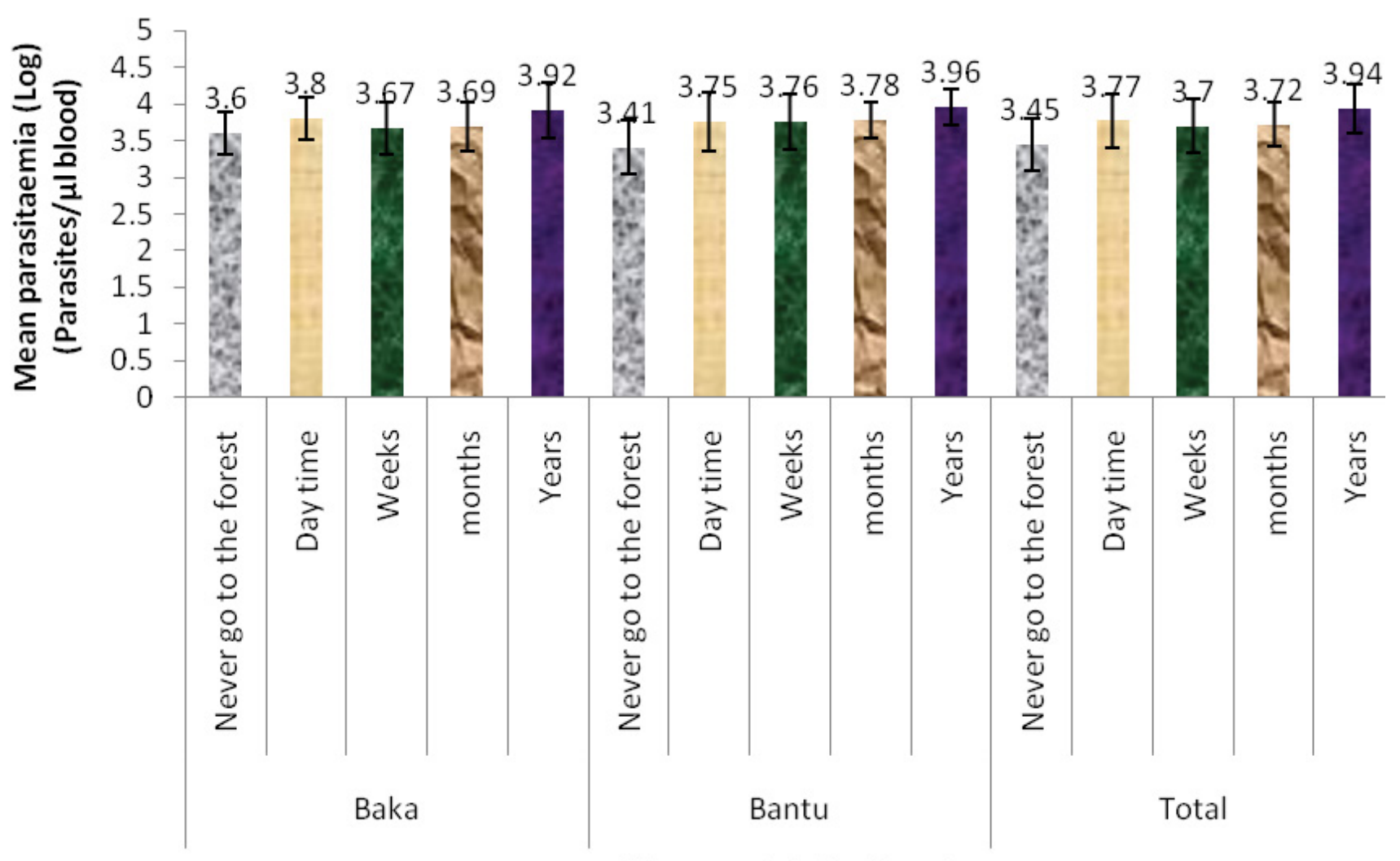

Time spent in the forest

Figure 4: Variation of parasitaemia according to the time spent in the forest and ethnicity. 
the highest the parasitaemia one carries $(11380 \pm 8086$ (2400-25333) and $10502 \pm 5966$ (4000-21714) parasites/ $\mu$ l blood respectively in Bakas and Bantus). In the Baka Pygmies as well as in Bantus, people who never go to the forest were less parasitized (4760 \pm 3558 (19519959) parasites/ $\mu \mathrm{l}$ blood and $3702 \pm 3976$ (711-16000) parasites/ $\mu$ l blood respectively) than people of all others groups $(P=0.02)$. Ethnic group doesn't influenced the distribution of parasitaemia according to time spent in the forest $(P=0.18)$.

\section{Discussion}

This study revealed that asymptomatic Baka pygmies as well as Bantus were able to tolerate approximately the same Plasmodium parasitaemia (462-72000 parasites/ $\mu$ l blood) without any sign of the disease. A similar range of parasitaemia was found by Nkuo-Akendjo, et al. [13] in Bolifamba, an atypical Cameroonian rainforest zone (38 - 50252 Trophozoïtes/ $\mu$ l blood). It would therefore seem that the activities of both the vector and the final host are similar within the two ethnic communities. In fact both Bakas and Bantus live in the same environments (village and forest).

Asymptomatic Bantus men tolerated high parasitaemia compared to females while in Bakas, the reverse result was observed. It may appear that Bantu male tend to spend more time outside at night in various outdoor activities (visits, meetings, drinking and other distractive activities).

The lower parasitaemia observed in infants of less than 2 years may be due to the fact that this age group still benefits from immunity acquired and transferred from mothers to the baby [16]. As from 2 to 5 years until 15 years, the number of people tolerating high parasitaemia increased. In general, children of endemic areas are able to develop the ability to tolerate high parasitaemia without any sign of morbidity $[6,17]$. Similarly, Richard, et al. [15] showed that in children from forest areas, the pyrogenic threshold was high (20 000 parasites $/ \mu$ ( blood). It is suggested that as people grow up, they are frequently exposed to vectors bites and this will make them resist to the toxic effects of parasites [15]. As individuals reach adult age, their malaria parasitaemia decreases, which is also supported by Jean, et al.[6] who found that $95 \%$ of asymptomatic adults had a parasite density of less than 500 trophozoïtes $/ \mu$ l blood. In fact, in malaria endemic areas, the immune system of non-treated adults, due to frequent re-infection, may prevent the multiplication and survival of malaria parasites [15].

In Baka pygmies, the most important parasitic load was observed in people who reached secondary education while in Bantus, it was the reverse. In fact, the study area has only one secondary school, so that most Bantus will move to the nearest towns (Abong-Mbang and Mindourou) for their secondary education. There, they acquire information on malaria (use of ITNs, modern treatment, environmental sanitation, etc...). Once back in the village, they are more likely to apply protective measures against malaria, hence their low Plasmodium parasitaemia. However among the Bakas on the other hand, secondary education is always local and it is permanently disrupted by the frequent migrations of the family towards the forest. Knowledge related to the prevention and treatment of malaria will not differ much from that acquired in primary school. This explains why parasitaemia in Bakas was not influenced by the level of education.

The intensity of Plasmodium infection is also characterized by seasonal fluctuations linked to larval breeding sites, human activities and rainfall [18]. The highest parasitaemia occurred during the small rainy season because mosquito activity is at its peak, water accumulates in gutters, pits, containers, abandoned tires, leaves, water reservoirs around homes, offices, market places and schools [19]. This creates a diversity of breeding sites for malaria vectors, increasing exposure to mosquito bites hence to infection and finally promoting high immunity against Plasmodium parasite [18]. This means, when the frequency and amount of rainfall decrease, the people's vulnerability to malaria increases [20]. On the other hand, during the main rainy season, when mains activities (hunting, fishing and agriculture) slowed down Plasmodium parasitaemia was low. Indeed, with animals hidden in their burrows, hunting becomes less attractive. At the same time, the high water level of rivers does not facilitate the effective practice of fishing. Agricultural activities are disturbed by heavy rains which often cause the leaching of crops. For these reasons, the inhabitants of the study area tend to spend more time indoors during the main rainy season, reducing contact with mosquito vectors and hence, reducing parasitaemia.

The most used modes of treatment in the study area were traditional medicine and self-medication probably because access to health centers is generally difficult in rural areas. Bantu people who combined three modes of treatment (traditional medicine, modern treatment and self-medication) tolerated the highest parasitic load. On the other hand, Baka pygmies who treated their malaria with a combination of self-medication and modern treatment were those harboring the highest parasite load. The frequent consumption of anti-malarial treatment as well as the frequent exposition to mosquito bites may have enhanced the immune system of participants and tackle the toxic effects of the parasites.

Certain occupations expose more to malaria than others [21,22]. The highest Plasmodium parasitaemia observed in Bantus logging company workers may be due to the frequent exposition to vector bite during the discharge of their duties in the forest. In fact, Ricci [23] have demonstrated in his studies that there is a 
significant link between regular work in the forest and increased risk of malaria.

Forests seem to be areas of high malaria endemicity $[24,25]$. That is why people who spend more of their time in the forest harbored high Plasmodium parasitaemia. Indeed, tree canopy provides shade even during the hottest hours of the day and humidity protects mosquitoes from estivation and death. Moreover, in the forest, there are protected breeding pools, rich in nutrients, which favor the development of vectors. Most of all, people living or working in forest don't have protected infrastructure or any vector-control measures [17].

\section{Conclusion}

At the end of this work which aimed to determine the threshold Plasmodium parasitaemia among malaria asymptomatic indigenous communities, it turned out that in Bakas as well as in Bantus, asymptomatic individuals were able to carry more than 55,000 (56000 in Baka and 72,000 in Bantus) trophozoïtes/ $\mu$ l blood without any sign of the disease. Plasmodium parasitaemia was mainly influenced by the age and level of education of hosts, season, and by time spent in the forest, not significantly by ethnicity as initially hypothesized.

\section{Recommendation}

A KAP (knowledge, attitude and practice) study in this population is necessary to help design a malaria control strategy ratified by the Ministry of Public Health in the perspective of malaria eradication in forest area.

\section{Limitation}

Plasmodium falciparum was the only malaria parasite discovered in this study. The study was supposed to stays about 2 years but the difficulty in getting the assistance of the head of the health center for a longer period has shorten the study period. The sample study was heterogeneous; some factors collected were not statically analyses. It would have been interesting to follow those asymptomatic carriers over the time, in order to determine the threshold Plasmodium parasitaemia needed to initiate malaria symptoms.

\section{Acknowledgements}

We appreciate the assistance offered us by the laboratory of the District Hospital of Abong Mbang and by the members of united research of Biology and Apply Ecology.

\section{Conflict of Interest}

The authors declared that there is no conflict of interest.

\section{References}

1. Minsanté Onzième (2018) Journée mondiale de lutte contre le paludisme "prêt à vaincre le paludisme" Nous sommes la génération qui peut éliminer le paludisme. Dossier de Presse 1-20.
2. World Health Organization (WHO) (2015) World malaria report 2015. Geneva.

3. Mbako JD, Barffo D, Kuuzagr NR, Alebshehy R, Shuaib NM (2017) Enhancing malaria prevention in Cameroon through community participation: An in-depth review. Cent Afri J Pub Health 3: 97-109.

4. Sompwe EM, Cilundika MP, Mashinda KD, Lutumba TP Mapatano MA, et al. (2016) Parasitémie asymptomatique chez les enfants de moins de 5 ans, enfants en âge scolaire et prise en charge des épisodes fébriles dans les ménages de Lubumbashi, République Démocratique du Congo. Pan Afri Med J 24: 94.

5. Lindblade KA, Steinhardt L, Samuels A, Kachur SP, Slutsker L (2013) The silent threat: Asymptomatic parasitemia and malaria transmission. Expert Rev Anti Infect Ther 11: 623-639.

6. Jean-Philippe C, Martin A, Achille M, Jerome A (1988) Mesure de la parasitémie palustre et évaluation du seuil pathogène en région de forte transmission permanente 55-65.

7. Blánaid D, Berrang-Ford Lea, Labbé J, Twesigomwe S, Lwasa S, et al. (2016) Plasmodium falciparum malaria parasitaemia among indigenous Batwa and non-indigenous communities of Kanungu district, Uganda. Malar J 15: 254.

8. Lehnebach C (2014) Caractérisation du socio-écosystème "Mindourou" (Cameroun) et identification des stratégies d'acteurs. Mémoire de Master, Université de Liège, 117.

9. Gangueu DCD, Yondo J, Noumedem ACN, Nkouayep VR, Mpoame Mbida (2020) Malaria susceptibility among indigenous Baka pygmies and Bantu in the Upper Nyong Division, Cameroon. Euro J Phar Med Res 7: 559-565.

10. Commune d'Abong Mbang (2013) Monographie de la Commune d'Abong Mbang. Etat des lieux prospectif 45.

11. Pierson A Biologie Clinique. Installation d'un laboratoire d'analyses médicales autonome dans un pays en développement 1998-2001 231

12. Dennis AG, Mohammed A, Sabastina A, Emmanuel $M$, Maxwell N, et al. (2012) Estimating malaria parasite density: Assumed white blood cell count of $10,000 / \mu \mathrm{l}$ of blood is appropriate measure in Central Ghana. Malaria J 11: 238.

13. Nkuo-Akenji T, Ntonifor NN, Ndukum MB, Abongwa EL, Nkwescheu A, et al. (2006) Environmental factors affecting malaria parasite prevalence in rural Bolifamba, South-West Cameroon. Afr J Health Sci 13: 40-46.

14. Valiathan R, Ashman M, Asthana D (2016) Effects of ageing on the immune system: Infants to elderly. Scand J Immunol 83: 255-266

15. Richard A, Lallemant M, Trape JF, Carnevalle P, Mouchet J (1988) Le paludisme dans la région forestière de Mayombe, République populaire du Congo : Place du paludisme dans la morbidité générale. Ann Soc Belge Méd Trop 68: 317329.

16. Rupashree S, Igboanua IG, Sanjay S, Rajendra BS, Nike TI, et al. (2014) High prevalence of asymptomatic malaria in apparently healthy schoolchildren in Aliero, Kebbi state, Nigeria. J Vector Borne Dis 51: 128-132.

17. Mouchet J, Carnevale P, Coosemans M, Fontenille D, Ravaonjanahary C, et al. (1993) Typologie du paludisme en Afrique. Cahier Santé 3: 220-238.

18. Ito EE, Egwunyenga AO, Ake JEG (2014) Prevalence of malaria and human blood factors among patients in Ethiope East, Delta State, Nigeria. Inter J Med Biomed Res 3: 191201. 
19. Prathiba M, De Silva, John MM (2012) Factors contributing to urban malaria transmission in Sub-Saharan Africa: A systematic review. Hindawi Journal of Tropical Medicine 2012: 10.

20. Yao KMA (2015) Farming communities vulnerability to malaria under climate change conditions in the bole district, northern region, Ghana. Thesis of Master Research in climate change and human security. University of LOME-Togo, 93.

21. Bogdan J, Waclaw N, Jolanta G, Iwona Felcxak-K, Jacek G, et al. (1996) Malaria as an occupational disease in polish citizens. J Travel Med 3: 22-26.

22. Abraham D, Kristopher F, Dawit D, Shasank C, Purnima M (2019) Improving socioeconomic status may reduce the burden of malaria in sub Saharan Africa: A systematic review and meta-analysis. PLoS One 14: e0211205.

23. Ricci $F$ (2012) Social implications of malaria and their relationships with poverty. Mediterr J Hematol Infect Dis 4: e2012048.

24. Lorenz VS, Thomas JP, Rupam T, Christopher P, Shunmay Y, et al. (2019) Novel approaches to control malaria in forested areas of Southeast Asia. Trends Parasitol 35: 388-398.

25. Chaves LSM, Conn JE, López RVM, Sallum MAM (2018) Abundance of impacted forest patches less than $5 \mathrm{~km}^{2}$ is a key driver of the incidence of malaria in Amazonian Brazil. Sci Rep 8: 7077. 